\title{
Synthesis of and in vitro and in vivo evaluation of a novel TGF-ß1-SF-CS three-dimensional scaffold for bone tissue engineering
}

\author{
SHUANG TONG, DA-PENG XU, ZI-MEI LIU, YANG DU and XU-KAI WANG \\ Department of Oral and Maxillofacial Surgery, School of Stomatology, China Medical University, \\ Liaoning Institute of Dental Research, Shenyang, Liaoning 110002, P.R. China
}

Received April 16, 2015; Accepted May 23, 2016

DOI: $10.3892 /$ ijmm.2016.2651

\begin{abstract}
The role of transforming growth factor- $\beta 1$ (TGF- $\beta 1$ ) in normal human fracture healing has been previously demonstrated. The objective of the present study was to examine the biocompatibility of TGF- $\beta 1$-silk fibroin-chitosan (TGF- $\beta 1-S F-C S$ ) three-dimensional (3D) scaffolds in order to construct an ideal scaffold for bone tissue engineering. We added TGF- $\beta 1$ directly to the SF-CS scaffold to construct a 3D scaffold for the first time, to the best of our knowledge, and performed evaluations to determine whether it may have potential applications as a growth factor delivery device. Bone marrow-derived mesenchymal stem cells (BMSCs) were seeded on the TGF- $\beta 1-S F-C S$ scaffolds and the silk fibroin-chitosan (SF-CS) scaffolds. On the TGF- $\beta 1-S F-C S$ and the SF-CS scaffolds, the cell adhesion rate increased in a time-dependent manner. Using a Cell Counting Kit-8 (CCK-8) assay and analyzing the alkaline phosphatase (ALP) expression proved that TGF- $\beta 1$ significantly enhanced the growth and proliferation of BMSCs on the SF-CS scaffolds in a time-dependent manner. To examine the in vivo biocompatibility and osteogenesis of the TGF- $\beta 1-S F-C S$ scaffolds, the TGF- $\beta 1-S F-C S$ scaffolds and the SF-CS scaffolds were implanted in rabbit mandibles and studied histologically and microradiographically. The 3D computed tomography (CT) scan and histological examinations of the samples showed that the TGF- $\beta 1-S F-C S$ scaffolds exhibited good biocompatibility and extensive osteoconductivity with the host bone after 8 weeks. Moreover, the introduction of TGF- $\beta 1$ to the SF-CS scaffolds markedly enhanced the efficiency of new bone formation, and this was confirmed using bone mineral density (BMD) and biomechanical evaluation, particularly at 8 weeks after
\end{abstract}

Correspondence to: Dr Xu-Kai Wang, Department of Oral and Maxillofacial Surgery, School of Stomatology, China Medical University, 117 Nanjing North Street, HePing District, Shenyang, Liaoning 110002, P.R. China

E-mail: wangxukai757892@sina.com

Key words: silk fibroin, chitosan, bone tissue engineering, transforming growth factor- $\beta 1$ implantation. We demonstrated that the TGF- $\beta 1-S F-C S$ scaffolds possessed as good biocompatibility and osteogenesis as the hybrid ones. Taken together, these findings indicate that the TGF- $\beta 1-S F-C S$ scaffolds fulfilled the basic requirements of bone tissue engineering, and have the potential to be applied in orthopedic, reconstructive and maxillofacial surgery. Thus, TGF- $\beta 1-S F-C S$ composite scaffolds represent a promising, novel type of scaffold for use in bone tissue engineering.

\section{Introduction}

The repair of bone defects resulting from tumors, congenital malformations and surgical resections remains a challenge that is being addressed by advanced bone tissue engineering approaches $(1,2)$. A combined approach for treating large bone defects including the use of cell seeding techniques, growth factors and biomaterials further enhances the success of cell therapy $(3,4)$. The interactions between various growth factors involved in bone healing and remodeling has been extensively studied in recent years. The role of transforming growth factor- $\beta 1$ (TGF- $\beta 1$ ) in normal human fracture healing has been demonstrated in a previous study (5). TGF- $\beta 1$ is known to induce the differentiation and proliferation of osteoblasts and bone marrow-derived mesenchymal stem cells (BMSCs), and also to stimulate the appearance of extracellular matrix (ECM) proteins in vitro $(6,7)$. TGF- $\beta 1$ has been widely used to promote the osteogenesis of BMSCs in a variety of in vitro culture systems by continuously supplying it in the medium for $>4$ weeks (8-10). Thus, the controlled administration of TGF- $\beta 1$ may represent an emerging tissue engineering technology that modulates cellular responses to encourage bone regeneration at the site of a skeletal defect $(11,12)$.

BMSCs are multipotent progenitor cells that have the ability to differentiate into mesenchymal lineages, including osteoblasts, chondrocytes and adipocytes (13). The differentiation and function of BMSCs is regulated by TGF- $\beta 1$. For example, TGF- $\beta 1$ stimulates the proliferation of BMSCs and promotes their differentiation into chondrocytes (14). TGF- $\beta 1$ promotes chondrogenesis as well as the early phase of osteogenesis; however, in the absence of bone morphogenetic proteins (BMPs), TGF- $\beta 1$ is unable to promote the differentiation of BMSCs into osteoblasts (15). Thus, in the present study, BMSCs 
were induced into osteoblast-like cells together with osteogenic medium prior to transplantation. Osteoblast-like cells derived from BMSCs share similar characteristics with osteoblasts. The present study evaluated the effects of BMSCs and of osteoblast-like cells differentiated from BMSCs, on TGF- $\beta 1$-silk fibroin-chitosan (TGF- $\beta 1-S F-C S$ ) scaffolds and silk fibroin-chitosan (SF-CS) scaffolds, as well as analyzing the effects of TGF- $\beta 1$ in SF-CS scaffolds and in vitro biocompatibility for the first time, to the best of our knowledge.

Both silk fibroin (SF) and chitosan (CS) are natural biomaterials with good biocompatibility which are available in abundance. It is, however, difficult to prepare a pure SF scaffold with a porous structure, and SF has poor anticoagulant properties. In addition, a pure CS scaffold degrades relatively quickly, and is unstable in aqueous solution(16-18). In ourprevious study (19), we blended SF and CS into a three-dimensional (3D) scaffold with unique chemical, structural and mechanical properties, which has potential applications in bone tissue engineering and regenerative medicine. Previously, it was found that the the most appropriate proportion between CS and SF is 5:5 for bone tissue engineering (20). Our current study at our laboratory is examining soluble growth factor supplementation schemes in order to enhance the bioactivity of bone cells for bone tissue engineering applications.

The optimal strategy for delivering growth factors to cells for the purposes of bone tissue engineering and bone repair remains an unmet challenge. For this purpose, we added TGF- $\beta 1$ into a SF-CS scaffold to construct a 3D scaffold for the first time to the best of our knowledge. In previous studies, growth factors were added to the medium, and then the growth factors in the solution were incorporated into the resulting polymer scaffolds and the sustained release of growth factors facilitated bone regeneration in vitro and in vivo (21-26). This approach was limited by the fact that the dose and spatial distribution of growth factors in these scaffold systems was uncontrolled. In another study, rapid drug delivery occurred in the early stages as the drug that was close to the surface was released or the drug easily diffused out of the bulk of the material until supplies were exhausted resulting in lower release rates (27). To address this issue, we aimed to explore the novel strategy of directly adding TGF- $\beta 1$ onto an SF-CS scaffold during SF-CS scaffold fabrication, rather than after scaffold fabrication. In the future, this novel strategy may be applied to pattern and immobilize other growth factors to the SF-CS 3D scaffolds developed herein. We discussed the application and biocompatibility of TGF- $\beta 1$-SF-CS scaffolds which meet the requirements of bone tissue engineering. One of the aims of our study was to ensure that the release of TGF- $\beta 1$ from the SF-CS scaffolds occurred at therapeutic levels and enhanced matrix production by BMSCs. The effect of TGF- $\beta 1-S F-C S$ scaffolds on the morphology, differentiation and function of BMSCs has not yet been studied and no study of this type has been performed previously on BMSCs, to the best of our knowledge. To examine the in vivo biocompatibility and osteogenesis of the TGF- $\beta 1-S F-C S$ scaffolds, both the TGF- $\beta 1-S F-C S$ scaffolds and the SF-CS scaffolds were implanted in rabbit mandibles and studied histologically and microradiographically. The effect of all the materials on morphogenesis was analyzed from the in vivo response in order to identify the clinical relevance of the SF-CS scaffold. We examined the ability of SF-CS scaffold-immobilized TGF- $\beta 1$ to drive TGF- $\beta 1$ bioactivity in the TGF- $\beta 1-S F-C S$ scaffolds. The sustained delivery of TGF- $\beta 1$ combined with the attractive mechanical properties of a biodegradable SF-CS scaffold may prove more advantageous for bone repair and regeneration. The present study enabled us to evaluate this technique as a potential method of constructing an ideal TGF- $\beta 1-S F-C S$ scaffold for bone tissue engineering. To the best of our knowledge, this is the first study to use TGF- $\beta 1-S F-C S$ composite scaffolds for mandibular repair.

\section{Materials and methods}

Animals and ethics statement. In the present study, we established an animal model to examine the repair of mandible defects using tissue engineering techniques. Eighteen healthy New Zealand white rabbits of either gender (3 months old, weighing approximately $3.0 \mathrm{~kg}$ ) were obtained from the Center for Experimental Animals at China Medical University (Shenyang, China) with a National Animal Use License number of SCXK-LN2011-0009. Animal use was approved by the Animal Use and Care Committee at China Medical University with a protocol number of CMU62043006. All experiments and surgical procedures were approved by the Animal Care and Use Committee at China Medical University, and complied with the National Institutes of Health Guide for the Care and Use of Laboratory Animals. All efforts were made to minimize the number of animals used and their suffering.

Materials. Raw silk was purchased from Nanchong Silk Co., Ltd. (Nanchong, China). Chitosan was purchased from Nantong Xing Cheng Biological Products Factory (Jiangsu, China). TGF- $\beta 1$ (100 ng/bottle) was purchased from ProSpec-Tany TechnoGene, Ltd. (Rehovot, Israel). Chemicals including $\mathrm{NaHCO}_{3}, \mathrm{CaCl}_{2}$ and ethanol were purchased from Jiancheng Biotechnology Institute (Nanjing, China). All other chemicals and reagents were of analytical grade unless specified otherwise.

Preparation of TGF- $\beta 1-S F-C S$ and SF-CS scaffolds. Bombyx mori silk fibers (Nanchong Silk Co., Ltd.) were treated with $0.5 \%$ (w/w) $\mathrm{NaHCO}_{3}$ solution twice at $100^{\circ} \mathrm{C}$ for $30 \mathrm{~min}$ and then rinsed with $70^{\circ} \mathrm{C}$ distilled water for $30 \mathrm{~min}$ to remove sericin. Degummed silk was dissolved in a mixed solvent system of $\mathrm{CaCl}_{2} / \mathrm{CH}_{3} \mathrm{CH}_{2} \mathrm{OH} / \mathrm{H}_{2} \mathrm{O}$ (mole ratio of $1: 2: 8$ ) at $70^{\circ} \mathrm{C}$ for $6 \mathrm{~h}$ and filtered to obtain a SF solution. The solution was dialyzed in cellulose dialysis tubing $(\mathrm{MWCO}=50,000)$ against distilled water for 3 days and the water was replaced every $12 \mathrm{~h}$ to remove all impurities. CS solutions were prepared by dissolving high molecular weight CS $(82.7 \%$ deacetylation; Tongxing Co.) at $3.66 \%(\mathrm{w} / \mathrm{v})$ in $2 \%$ acetic acid. The final concentration of CS used was $2 \%$.

TGF- $\beta 1$ solution was prepared by dissolving $100 \mathrm{ng}$ TGF- $\beta 1$ in $1 \mathrm{ml}$ deionised sterile water $(100 \mathrm{ng} / \mathrm{ml})$. The selected concentrations were based on the mid-range concentrations used in previous studies $(28,29)$.

SF/CS blend solutions $(100 \mathrm{ml})$ with a SF/CS weight ratio 5:5 were prepared in the same solvent system at $10 \mathrm{wt} \%$ (combined weight of CS and SF). Following dialysis in cellulose dialysis tubing $(\mathrm{MWCO}=50,000)$ against distilled water for 3 days with a water change every $12 \mathrm{~h}, \mathrm{CS}$ and SF solutions were obtained. TGF- $\beta 1$ solution $(1 \mathrm{ml})$ was then added and 
stirred with a magnetic stirrer for $50 \mathrm{~min}$. The CS, SF and TGF- $\beta 1$ solution was poured into a 24 -well Teflon culture plate. The CS, SF and TGF- $\beta 1$ solution was lyophilized (VFD-2000; Boyikang Laboratory Instruments Co., Ltd., Beijing, China) for a total time of $48 \mathrm{~h}$ to obtain TGF- $\beta 1-S F-C S$ scaffolds. We then prepared SF-CS scaffolds using the same method.

To improve water stability, the dry TGF- $\beta 1-S F-C S$ and SF-CS scaffolds were treated with methanol solution (concentration $<10 \%$ ) for $2 \mathrm{~h}$ to crystallize the SF content and neutralize the CS content. The TGF- $\beta 1-S F-C S$ and SF-CS scaffolds were lyophilized to remove excess methanol.

The dry TGF- $\beta 1-S F-C S$ and SF-CS scaffolds were fractured in liquid nitrogen using a razor blade. They were cut into square pieces of $0.5 \times 0.5 \mathrm{~cm}$ in size, placed on aluminum stubs with conductive adhesive tape composed of carbon, coated with gold using a JFC-110E Ion Sputter (Jeol USA, Inc., Peabody, MA, USA) for $60 \mathrm{sec}$ at $20 \mathrm{~mA}$ prior to observation under a scanning electron microscope (JSM-TM3000; Hitachi, Tokyo, Japan). Scanning electron microscopy (SEM) images and pore size were analyzed using ImageJ software. For each type of scaffold, a minimum of 30 pores were examined.

Determination of scaffold porosity and water absorption capacity. The porosity of the TGF- $\beta 1-S F-C S$ and SF-CS scaffolds was evaluated using hexane displacement (30). The scaffolds were immersed in a known volume $\left(V_{l}\right)$ of hexane. The total volume of hexane and hexane-impregnated scaffold was recorded as $V_{2}$. The volume difference $\left(V_{2}-V_{l}\right)$ was the volume of the polymer scaffold. Hexane-impregnated scaffold was removed, and the residual hexane volume was recorded as $V_{3}$. The porosity of the SF-CS scaffold was calculated as $\left[\left(V_{1}-V_{3}\right) /\left(V_{2}-V_{3}\right)\right] \times 100$.

The water absorption capacity of the TGF- $\beta 1-S F-C S$ and SF-CS scaffolds was determined by immersion in phosphate buffered saline (PBS; $\mathrm{pH} \mathrm{7.4)}$ ) at $37^{\circ} \mathrm{C}$ for $24 \mathrm{~h}$. At predetermined time intervals, three scaffold samples of each scaffold were carefully blotted to remove excess water and weighed. Wet weight $\left(W_{l}\right.$, swollen weight $)$ and dry weight $\left(W_{2}\right.$, dried at $37^{\circ} \mathrm{C}$ overnight) were measured. The water absorption capacity of the scaffold was calculated using the following formula: $\left[\left(W_{1}-W_{2}\right) / W_{2}\right] \times 100$.

The swelling ability of SF-CS scaffolds, using three samples/scaffold, was determined by immersion in PBS (pH 7.4) at $37^{\circ} \mathrm{C}$ for $24 \mathrm{~h}$. Wet volume $\left(S_{l}\right.$, swollen volume) and dry volume $\left(S_{2}\right.$, dried at $37^{\circ} \mathrm{C}$ overnight) were measured. The swelling index of the scaffold was calculated using the following formula: $\left[\left(S_{1}-S_{2}\right) / S_{2}\right] \times 100$.

Isolation, culture and differentiation of BMSCs. Prior to the surgical procedures, the rabbits were anesthetized with $10 \%$ chloral hydrate $(0.35 \mathrm{ml} / 100 \mathrm{~g})$ intraperitoneally. Bone marrow (3-5 ml) was extracted from rabbit femurs using a heparinized syringe, and then centrifuged and washed with PBS. The cell suspension was centrifuged with Percoll lymphocyte separation medium, and the ivory white layer in the middle was collected, washed with PBS and cultured in complete low-glucose Dulbecco's modified Eagle's medium (DMEM). The cells were seeded in culture flasks at a density of $1.0 \times 10^{4}$ cells $/ \mathrm{cm}^{2}$ and incubated at $37^{\circ} \mathrm{C}$ in a humidified atmosphere with $5 \% \mathrm{CO}_{2}$. Half of the culture medium was replaced after $24 \mathrm{~h}$, and completely replaced after $48 \mathrm{~h}$, followed by medium changes every 2-3 days. The unattached cells were discarded by refreshing the medium. The cells at $85 \%$ confluency were trypsinized, centrifuged and passaged at a 1:2 ratio. Third-passage cells were induced to differentiate with osteogenesis induction liquid $(0.1 \mu \mathrm{mol} / 1$ dexamethasone, $50 \mu \mathrm{mol} / \mathrm{ml}$ vitamin $\mathrm{C}, 10 \mathrm{mmol} / \mathrm{l} \beta$-glycerophosphate and $10 \%$ fetal bovine serum in glucose DMEM), followed by medium changes every 2-3 days. BMSC morphology at different time points was examined under a light-inverted microscope (CKX41; Olympus, Tokyo, Japan).

Alkaline phosphatase (ALP) staining and the von Kossa assay. ALP activity was evaluated in BMSCs 14 days after osteogenesis induction and in those without osteogenesis induction (control group). The cells were fixed for $10 \mathrm{~min}$ at $4^{\circ} \mathrm{C}$ and incubated with $2 \%$ cobalt nitrate and $1 \%$ ammonium sulfide (ALP kit; Hongqiao, Shanghai, China). Areas stained tan were designated as positive.

BMSCs plated in 6-well plates were fixed in $70 \%$ ethanol 18 days after osteogenesis induction and those without osteogenesis induction (control group). The cells were stained with von Kossa silver (Jiancheng Biotechnology Institute) and placed under ultraviolet (UV) light for $10 \mathrm{~min}$. The cells were then treated with $5 \% \mathrm{NaS}_{2} \mathrm{O}_{3}$ for $2 \mathrm{~min}$, and washed with distilled water. Calcium nodules with a diameter $>1 \mathrm{~mm}$ were visualized under a light-inverted microscope.

BMSC seeding onto scaffolds and morphological analysis. The scaffolds were sterilized with $75 \%$ alcohol under UV light overnight and then rinsed extensively three times with sterile PBS. Prior to cell culturing, the scaffolds were pre-wetted by immersion in DMEM for $12 \mathrm{~h}$ in an incubator at $37^{\circ} \mathrm{C}$.

The BMSCs were cultured onto TGF- $\beta 1-S F-C S$ scaffolds, SF-CS scaffolds and 24-well tissue culture plate wells (control group; $\mathrm{n}=3$; diameter $15 \mathrm{~mm}$; height $13 \mathrm{~mm}$ ) for 3 and 6 days after osteogenesis induction at $37^{\circ} \mathrm{C}$ under an atmosphere of $5 \% \mathrm{CO}_{2}$ and $95 \%$ air, with the original cell culture density of 4,000 cells/well.

BMSC morphology following osteogenesis induction on the TGF- $\beta 1$-SF-CS scaffold and the SF-CS scaffold was observed on days 1, 3 and 7 by SEM. The samples were washed with PBS and fixed with $3.0 \%$ glutaraldehyde at $4^{\circ} \mathrm{C}$ for $4 \mathrm{~h}$. Subsequently, they were dehydrated through a graded ethanol series $(30,50,70,80,90,95$ and 100\%), air-dried overnight, and sputtered with gold for SEM observation. Adherent cell morphology, patterns of cellular adherence with respect to structural features of the TGF- $\beta 1-S F-C S$ scaffold and the SF-CS scaffold, cell-cell interactions, and adherent cell density were assessed.

Adhesion of BMSCs to scaffolds. Following osteogenesis induction on the TGF- $\beta 1-S F-C S$ scaffold, the SF-CS scaffold and the control group, the BMSCs were harvested and the concentration was adjusted to $1 \times 10^{4} / \mathrm{ml}$. The cells were placed in cell culture plates pre-coated with TGF- $\beta 1-S F-C S$ scaffold and SF-CS scaffold at $1 \mathrm{ml} /$ well. The cells cultured in culture plates with no scaffold served as the controls. Three parallel wells were used for each group. The cells were cultured in an incubator at $37^{\circ} \mathrm{C}$ with $5 \% \mathrm{CO}_{2}$. The number of non-adherent 
cells was quantified at 1,3 and $6 \mathrm{~h}$. The cell adhesion rate (\%) was calculated as (number of seeded cells - non-adherent cells)/(number of seeded cells) x100.

Cell Counting Kit-8 (CCK-8) assay and ALP activity. To examine grafted cell survival, cell viability and proliferation was determined using a CCK-8 assay. After the samples were cultured for $1,3,5$ and 7 days, the culture medium was replaced with a serum-free culture medium containing CCK-8 $(0.5 \mathrm{mg} / \mathrm{ml})$. After $4 \mathrm{~h}$ of culturing, the samples were transferred to a 96-well plate. Absorbance was measured at $450 \mathrm{~nm}$ using an ELISA reader (Bio-Rad Model 550; Bio-Rad, Berkeley, CA, USA). Optical density (OD) at $450 \mathrm{~nm}$ was proportional to the number of cells.

Intracellular ALP activity in the scaffolds and the control group was measured using an ALP assay kit (Nanjing Jiancheng Bioengineering Institute, Nanjing, China). The samples were cultured for 1, 4, 7, and 10 days, and then washed with PBS three times. The samples and the control group with cells were immersed overnight in $500 \mathrm{ml}$ cell lysis solution containing $0.1 \%$ Triton X-100 and $5 \mathrm{mM} \mathrm{MgCl}_{2}$. The solution was transferred to a tube and centrifuged at 28,340 $\mathrm{x}$ g for $10 \mathrm{~min}$ at $4^{\circ} \mathrm{C}$. ALP activity was measured by mixing $50 \mu \mathrm{l}$ supernatant with $50 \mathrm{ml} p$-nitrophenyl phosphate $(5 \mathrm{mM})$ in $150 \mathrm{mM}$ 2-amino-2-methyl-1-propanol buffer solution at room temperature for $30 \mathrm{~min}$ in the dark. Following the incubation period, the reaction was stopped by adding $50 \mu 10.2 \mathrm{~N} \mathrm{NaOH}$ to denature ALP and the OD was measured at $520 \mathrm{~nm}$ using an ELISA reader (Bio-Rad Model 550; Bio-Rad).

Surgical procedure and implantation. The bone-forming ability of the TGF- $\beta 1-S F-C S$ scaffolds and the SF-CS scaffolds was assessed in the rabbit model of a submaxillary defect. The rabbits were randomly divided into the following 3 groups: i) the TGF- $\beta 1-S F-C S$ scaffolds group $(n=6)$; ii) the pure SF-CS scaffolds group $(n=6)$; iii) the non-scaffold as a control group $(n=6)$. The surgical procedures were performed under aseptic conditions. The rabbits were anesthetized with $10 \%$ chloral hydrate $(0.35 \mathrm{ml} / 100 \mathrm{~g})$ intraperitoneally, and the jaw was exposed and disinfected. Bilateral $3-\mathrm{cm}$ parallel incisions were made on the jaw of the rabbit. The periosteum was retracted and the submaxilla was exposed. A critical round full-thickness bone defect, $8 \times 8 \mathrm{~mm}^{2}$, was made in a buccal-lingual direction using a slow-speed dental drill on one side of the mandible that was cooled continuously. To avoid tissue damage due to overheating, $0.9 \%$ saline was dripped onto the contact point between the bur and bone. A $8 \times 8-\mathrm{mm}^{2}$ sized pure SF-CS scaffold or TGF- $\beta 1-S F-C S$ scaffold construct was inserted into the defect. To ensure that the bony defects were critically sized, rabbits in the control group had nothing inserted into the defect. The region of the defect was washed with normal saline, and the incision was sutured layer by layer. Penicillin (400,000 units) was intramuscularly injected over 3 days to prevent infection.

General observations, dual energy X-ray absorptiometry (DXA) analysis, and radiographic analysis. Following surgery, all rabbits were housed and fed routinely, and monitored for changes in their appearance, submaxilla movements, and healing of the surgical wounds. Additionally, the local bone mineral densities (BMDs) were measured on a Discovery DXA system (Hologic Inc.,
Bedford, MA, USA). 3D images of the mandibles were captured with a multi-slice spiral computed tomography (CT) scanner (GE Lightspeed Ultra 16; GE Healthcare, Milwaukee, WI, USA) at 12 weeks after implantation.

Biomechanical evaluation. Flexural modulus and peak flexural strength were measured. The specimens were tested to flexural failure in a three-point bending configuration with a $10-\mathrm{mm}$ spacing between the loading supports and a $20-\mathrm{mm}$ spacing between the base supports. The specimens were loaded in buccal-lingual orientation at a constant strain rate of $0.5 \mathrm{~mm} / \mathrm{min}$ on an Insight 5 uniaxial test frame (MTS Systems Corp., Eden Prairie, MN, USA).

Histomorphometric analysis of bone regeneration. Rabbits from each group were sacrificed at 4, 8 and 12 weeks after implantation by acute blood loss under anesthesia. To quantitatively determine the amount of newly formed bone, we statistically analyzed histological sections from different implantation periods. At every implantation time (4, 8 and 12 weeks), three histological sections were randomly chosen from the pure SF-CS scaffold, the TGF- $\beta 1-S F-C S$ scaffold and the control groups. These specimens were fixed in $4 \%$ paraformaldehyde, embedded in paraffin and serial buccal and lingual sagittal cross sections were made, which was followed by staining with hematoxylin and eosin (H\&E; Jiancheng Biotechnology Institute). Each section was then observed under a light microscope (CKX41; Olympus) at x100 magnification, and at least 5 images were randomly obtained from one section. Using image analysis software Image-Pro Plus (Media Cybernetics, Inc., Rockville, MD, USA), new bone volume (NBV) was expressed as the percentage of newly formed bone area in the available pore space (bone area/pore area x100).

Statistical analysis. All quantitative data are expressed as the means \pm standard deviation. Statistical analyses were performed using the statistic program SPSS 17.0. The results were analyzed by one-way analysis of variance (ANOVA) with a Student's t-test. A P-value $<0.05$ was considered to indicate a statistically significant difference. Before the results were analyzed by one-way ANOVA, all quantitative data obeyed the normality distribution.

\section{Results}

Evaluation of porosity and water absorption capacity of scaffolds. With the addition of TGF- $\beta 1$, the pore size and porosity of SF-CS scaffolds increased, although the difference was not significant $(\mathrm{P}>0.05)$. The hexane displacement experiment demonstrated that the porosity of the TGF- $\beta 1-S F-C S$ scaffolds $(90.2 \pm 4.6 \%)$, as well as the pore size $(236 \pm 73 \mu \mathrm{m})$ (Table I), may facilitate nutrient and waste transport into and out of the scaffolds.

Water absorption capacity, swelling ability and retain ability are other important factors in determining the usefulness of the biomaterials. The absorption capacity of the TGF- $\beta 1-S F-C S$ and SF-CS scaffolds was measured in terms of the degree of swelling at equilibrium. It was found that the degree of swelling of the scaffolds was in range of $24-26 \%$ of their dry weight and the difference was not significant (P>0.05) following the addition of TGF- $\beta 1$ (Table I). The 
Table I. Porosity, swelling and water absorption of TGF- $\beta 1$-SF-CS and SF-CS scaffolds.

\begin{tabular}{lcccc}
\hline & Porosity $(\%)$ & Pore size $(\mu \mathrm{m})$ & Water absorption $(\%)$ & Swelling index $(\%)$ \\
\hline TGF- $\beta 1-S F-C S$ & $90.2 \pm 4.6$ & $236 \pm 73$ & $271 \pm 12$ & $25.6 \pm 0.4$ \\
SF-CS & $89.5 \pm 7.9$ & $220 \pm 91$ & $282 \pm 4$ & $24.5 \pm 0.5$ \\
\hline
\end{tabular}

Results are expressed as the means $\pm \operatorname{SD}(n=3)$. $P>0.05$.
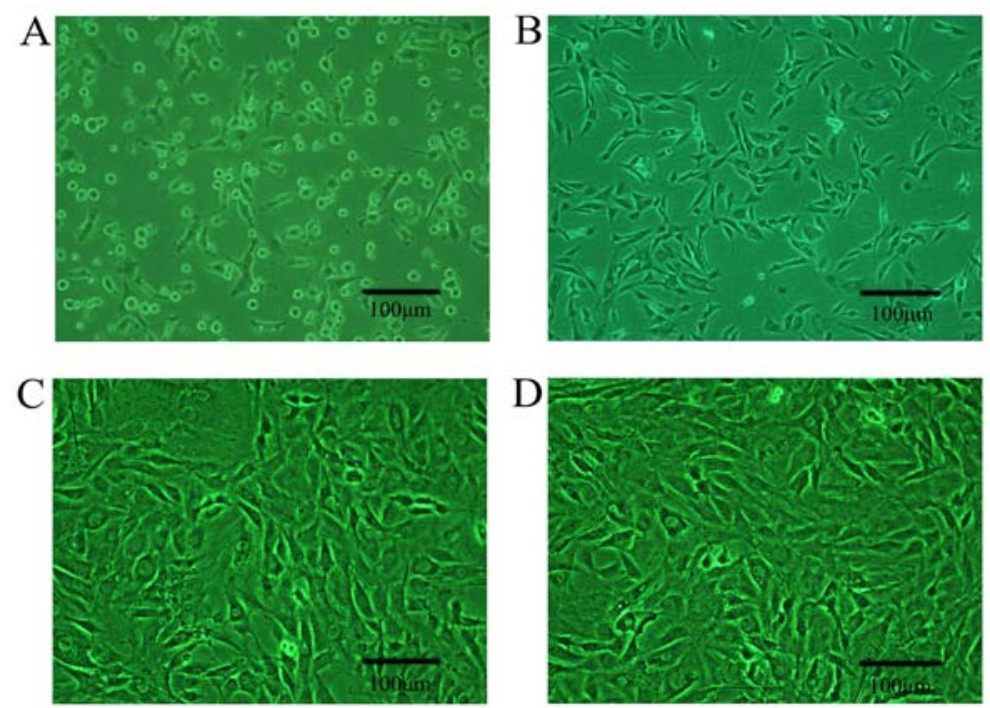

Figure 1. Cell morphology of bone marrow-derived mesenchymal stem cells (BMSCs) observed under a light-inverted microscope. (A) Primary cells. (B) BMSCs cultured for 3 days. (C) BMSCs cultured for 12 days; (D) Third passage BMSCs.

TGF- $\beta 1-S F-C S$ and SF-CS scaffolds, which exhibited a high degree of swelling and water absorption, also retained their structure after immersion in PBS (pH 7.4) for $24 \mathrm{~h}$.

Cell morphology and osteogenic differentiation of BMSCs. Cell morphology was studied using a light-inverted microscope (Fig. 1). The BMSCs demonstrated good survival and rapid proliferation.

In primary cells, BMSCs exhibited a round morphology. After $12 \mathrm{~h}$, the BMSCs were attached to the culture flasks sparsely and displayed a fibroblast-like, spindle-shaped morphology (Fig. 1A). After 3-4 days of incubation, cell numbers increased, the cells continued to grow well and actively proliferate and the cells gradually grew into small colonies, and they assumed a more spindle-shaped, fibroblastic morphology (Fig. 1B). After 10-12 days, the majority of the cells were attached and had acquired a large, flattened or multilayer growth morphology (Fig. 1C) which remained unchanged throughout subsequent passages (Fig. 1D).

Two weeks later, ALP staining was greater in the BMSCs after osteogenesis induction (Fig. 2A) than in those without osteogenesis induction (Fig. 2B). In addition, Von Kossa staining 2 weeks after osteogenesis induction (Fig. 2C) revealed a significant increase in calcium nodules compared with that in the BMSCs without osteogenesis induction (Fig. 2D).

Adhesion rate of BMSCs. After 1, 3 and $6 \mathrm{~h}$, the cell adhesion rate increased in all three groups, in a time-dependent manner (Fig. 3). The adhesion rates in the TGF- $31-$ SF-CS group and the SF-CS group were higher than those in the control group $(\mathrm{P}<0.01)$. At $1 \mathrm{~h}$, the adhesion rate in the SF-CS scaffold group was nearly the same as that in the TGF- $\beta 1-S F-C S$ scaffold group; there were no significant differences between the scaffold groups $(\mathrm{P}>0.05)$. After $3 \mathrm{~h}$, there was a significant increase in the adhesion rate compared with the groups at $1 \mathrm{~h}$. The adhesion rate in the TGF- $\beta 1$-SF-CS group and the SF-CS group was significantly higher than that in the control group $(\mathrm{P}<0.05)$; however, there was still no significant difference between the scaffold groups $(\mathrm{P}>0.05)$. These results have-proved that the SF-CS scaffolds increased BMSC adhesion-and that TGF- $\beta 1$ was unable to promote BMSC adhesion in the SF-CS scaffolds.

SEM images of TGF- $\beta 1$-SF-CS scaffolds and BMSCs cultured with the TGF- $\beta 1-S F-C S$ scaffolds. Following the addition of TGF- $\beta 1$, the morphology of the scaffolds did not change markedly. SEM revealed that all of the TGF- $\beta 1$-SF-CS scaffolds and the SF-CS scaffolds exhibit porous structures (Fig. 4). The composite of TGF- $\beta 1-S F-C S$ scaffolds was mixed well by a homogeneous method. A smooth surface is observable in the SEM images. The TGF- $\beta 1$-SF-CS scaffolds exhibit well-oriented, porous structures from the surface to the inside which may be beneficial for cell seeding and distribution (Fig. 4A). The TGF- $\beta 1-S F-C S$ scaffold with fully porous structures may facilitate uniform cell seeding and nutrient delivery, which are important for cell growth in a 3D porous scaffold. To measure the pores in the TGF- $\beta 1$-SF-CS scaffolds, 

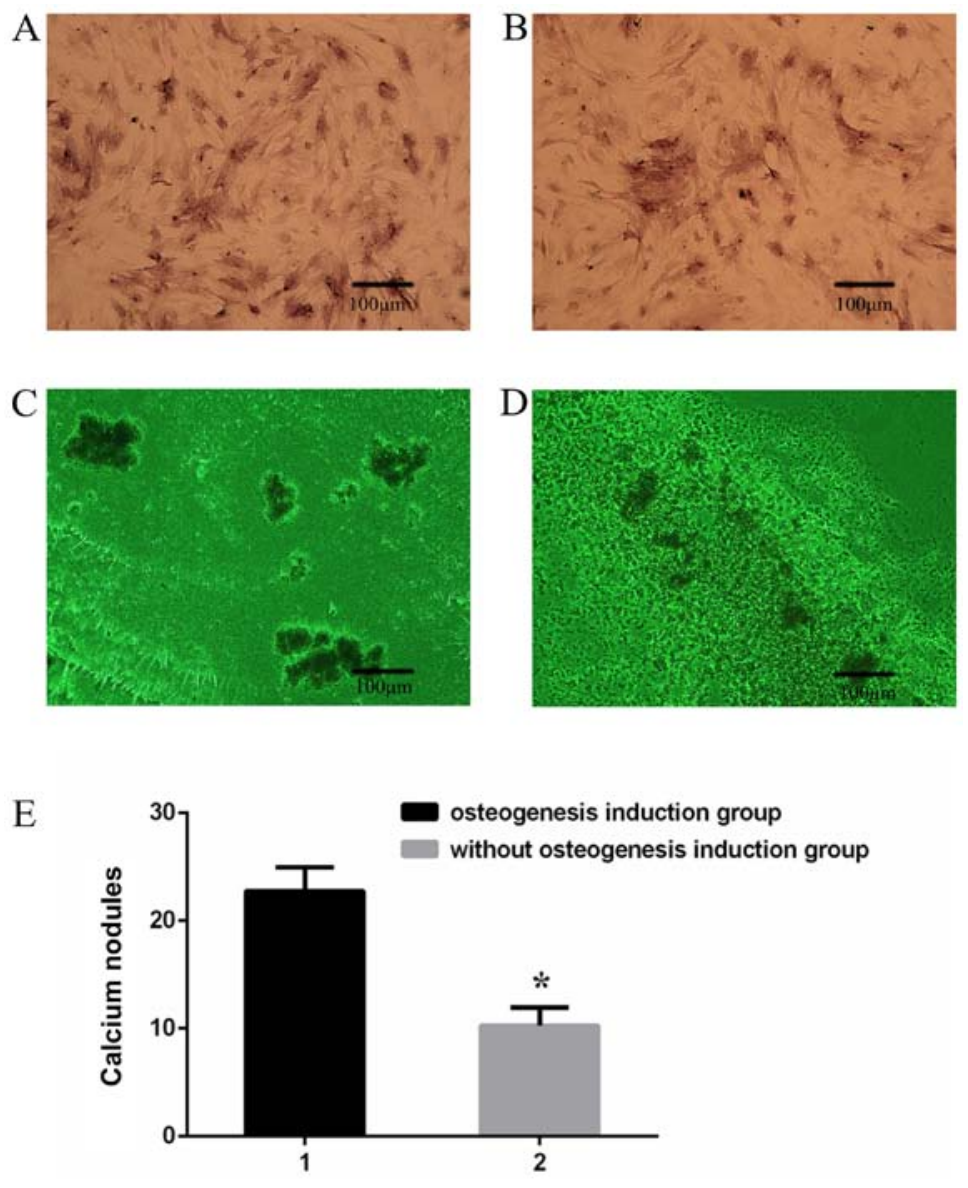

Figure 2. In vitro analysis of osteogenic differentiation in bone marrow-derived mesenchymal stem cells (BMSCs) following osteogenesis induction and in those without osteogenesis induction. (A) Alkaline phosphatase (ALP) staining 14 days after osteogenesis induction in BMSCs. (B) ALP staining on day 14 in BMSCs without osteogenesis induction. Von Kossa assay examining the presence of calcium nodules in (C) BMSCs following osteogenesis induction and (D) in BMSCs without osteogenesis induction after 18 days of culture. (E) Quantitative analysis of calcium nodules present in the two groups. A significant increase was seen in BMSCs in the osteogenesis induction group compared with that in the BMSCs without osteogenesis induction group; ${ }^{*} \mathrm{P}<0.05$.

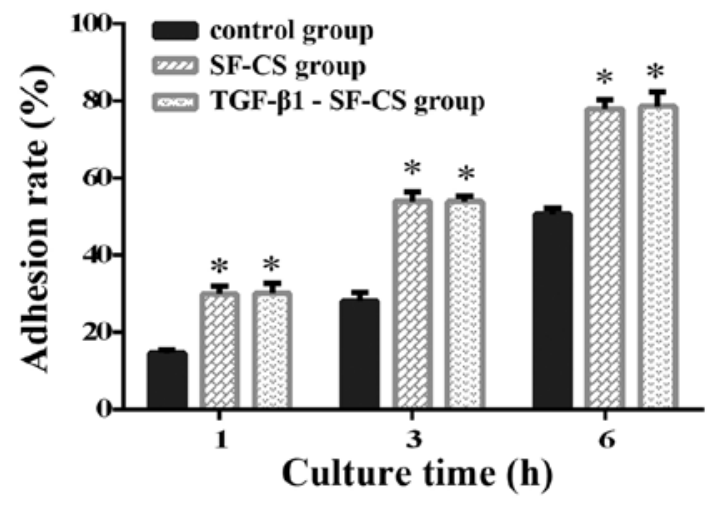

Figure 3. Adhesion rate of bone marrow-derived mesenchymal stem cells (BMSCs) in TGF- $\beta 1$-silk fibroin-chitosan (TGF- $\beta 1$-SF-CS) scaffolds, silk fibroin-chitosan (SF-CS) scaffolds and the control group. ${ }^{*} \mathrm{P}<0.05$ compared with the control group at the same time-point.

the scaffold was cut transversely to expose the internal porous structures. The TGF- $\beta 1-S F-C S$ scaffolds exhibited a homogeneous pore structure. The inner pore size of the TGF- $\beta 1-S F-C S$ scaffolds was approximately 10-300 $\mu \mathrm{m}$. Fig. 4B shows that the pore wall of the TGF- $\beta 1$-SF-CS scaffold has a smooth surface morphology and the width of the pore wall is approximately 1-2 $\mu \mathrm{m}$. The homogeneous pore wall section morphology shows that TGF- $\beta 1, \mathrm{SF}$ and CS are compatible, even at nanoscale. Fig. 4C shows that the SF-CS scaffold has a similar morphology to the TGF- $\beta 1$-SF-CS scaffold. This result suggests that TGF- $\beta 1$, SF and CS may be combined to generate a composite scaffold, possessing the advantages of the growth factor and two naturally-derived biomaterials.

The growth of osteogenically-induced BMSCs on scaffolds, cellular attachment and interactions within the TGF- $\beta 1$-SF-CS scaffold were evaluated by electron microscopy. The SEM images reveal that BMSCs are present on the surfaces and the pores of the scaffolds. The SEM images also show that on the TGF- $\beta 1-S F-C S$ scaffold, there are a number of BMSCs present that extend towards other cells in the culture.

On day 1, BMSCs seeded onto the scaffold had a distinct, round morphology and a large number of particles were observed on the cell surface, characterized by numerous plasma membrane microstructural extensions. Adherent BMSCs were observed preferentially localized to the fold regions of the TGF- $\beta 1$-SF-CS sheets, with BMSCs noted among fibrils projecting outwards from the scaffold edges (Fig. 4D).

After 3 days of culture, a large number of cells are adhered to the scaffold. The cell aggregates are enlarged and have actively proliferated. The SEM images reveal that the BMSCs 

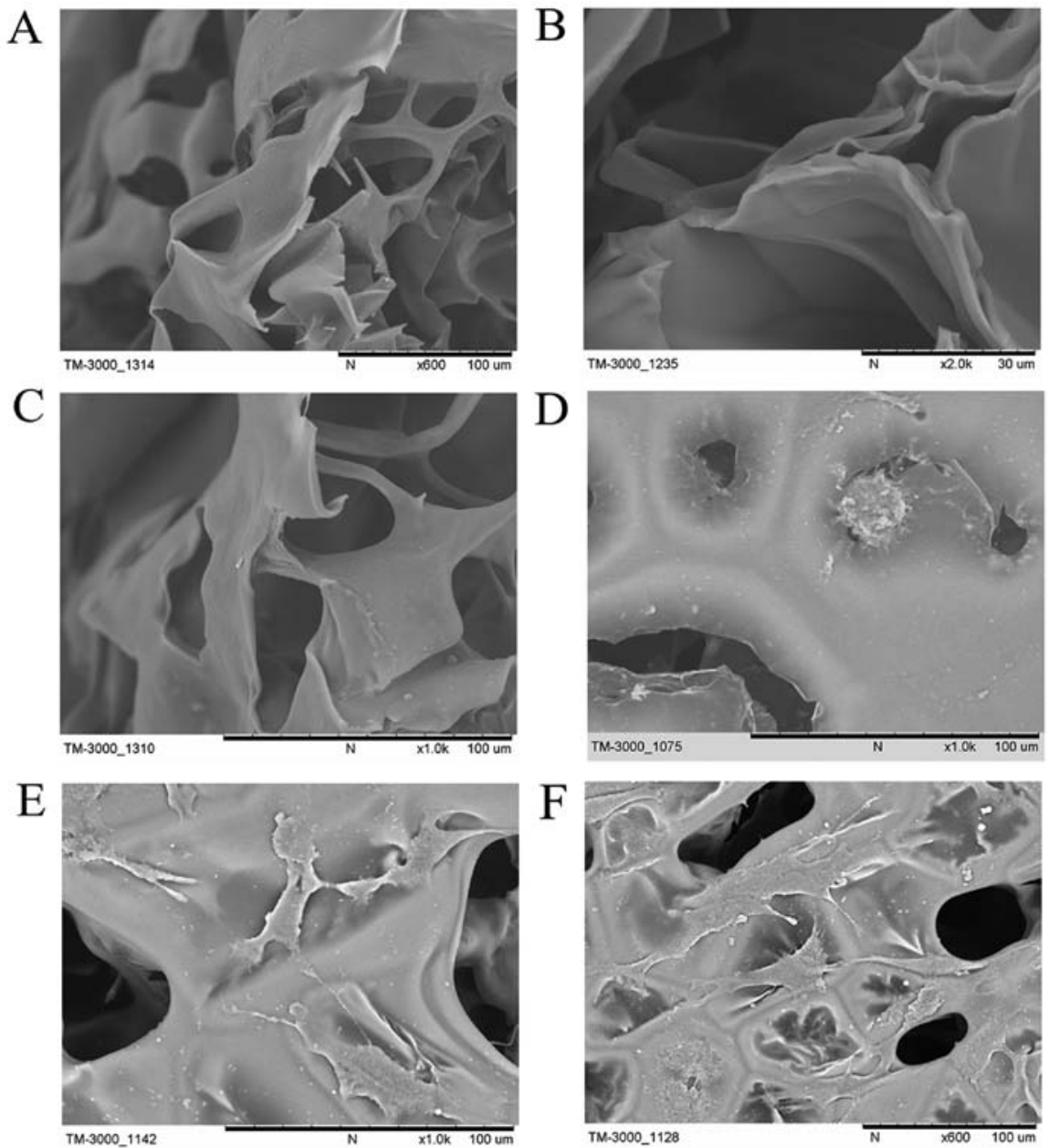

Figure 4. Scanning electron microscopy (SEM) images of the scaffolds and the bone marrow-derived mesenchymal stem cells (BMSCs) cultured with the TGF- $\beta 1$-silk fibroin-chitosan (TGF- $\beta 1-S F-C S$ ) scaffolds. (A) The TGF- $\beta 1-S F-C S$ scaffolds exhibit well-oriented, porous structures from the surface to the inside. (B) The pore wall surface and section morphology of the TGF- $\beta 1-S F-C S$ scaffold. (C) The silk fibroin-chitosan (SF-CS) scaffold has similar morphology to the TGF- $\beta 1$-SF-CS scaffold. (D) The BMSCs cultured with the TGF- $\beta 1-S F-C S$ scaffolds on day 1 ; (E) The BMSCs cultured with the TGF- $\beta 1-S F-C S$ scaffolds on day 3; (F) The BMSCs cultured with the TGF- $\beta 1-S F-C S$ scaffolds on day 7.

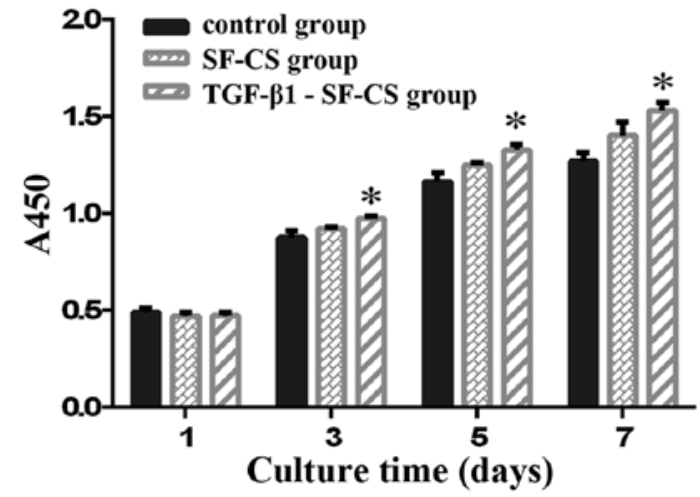

Figure 5. Cell Counting Kit-8 (CCK-8) assay to determine the proliferation of bone marrow-derived mesenchymal stem cells (BMSCs) cultured in different scaffolds and the control group. The TGF- $\beta 1$-silk fibroin-chitosan (TGF- $\beta 1$-SF-CS) scaffold markedly enhanced the proliferation of BMSCs after the 3rd day. ${ }^{*} \mathrm{P}<0.05$ compared with the silk fibroin-chitosan (SF-CS) group at the same time-point.

have spread to the scaffold surface and the pores, and they exhibit a flat and elongated morphology. Granular and filiform substances are observable around the cells, with microvilli and larger lamellipodia extensions extending from the BMSCs localized to the scaffold. The cells initially exhibit a stereo spindle and dendritic morphology at day 3 (Fig. 4E).

At day 7, the BMSCs have spread wider and deeper into the scaffold, an increased number of cells are adhered to the surface and the pores of the scaffold compared with that at day 3 , and the cells have grown and proliferated well. They exhibit typical osteoblast cell morphology and adhere tightly to the surface of the scaffold or inside, by forming lamellipodia and filopodia. Cell-cell interactions are also observable on the surface of the TGF- $\beta 1$-SF-CS scaffold as evidenced by connection of the fibrous extensions between two BMSCs. Similar cellular spreading and cell-cell interactions are apparent in more cells spread throughout the scaffold, which is crucial for the viability and function of BMSCs in vitro (Fig. 4F).

CCK-8 assay and ALP activity. The proliferation of BMSCs on the TGF- $\beta 1$-SF-CS scaffolds, the SF-CS scaffolds and in the control group cultured for 1,3,5 and 7 days were compared using a CCK-8 assay (Fig. 5). The absorbance index of the three groups increased with the increase in culture time, which indicated that significant cell growth had occurred within 


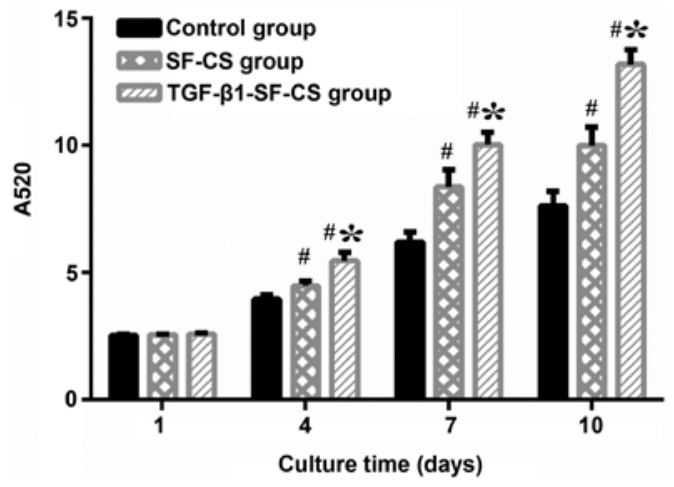

Figure 6. Alkaline phosphatase (ALP) assay to determine the proliferation of bone marrow-derived mesenchymal stem cells (BMSCs) cultured on different scaffolds, and the control group. The TGF- $\beta 1$-silk fibroin-chitosan (TGF- $\beta 1-S F-C S$ ) scaffold markedly enhanced the intracellular ALP activity of BMSCs after the 4 th day. ${ }^{*} \mathrm{P}<0.05$ compared with silk fibroin-chitosan (SF-CS) group at the same time-point. ${ }^{\text {}} \mathrm{P}<0.05$ compared with the control group at the same time-point.

both scaffolds. The data regarding BMSCs cultured without scaffolds is also present. The BMSCs proliferated well in the TGF- $\beta 1-S F-C S$ scaffolds and the SF-CS scaffolds, and there were no significant differences with the cells cultured in the control group at day $1(\mathrm{P}>0.05)$. However, after 3 days, more proliferation was observed in the BMSCs cultured on the TGF- $\beta 1-S F-C S$ scaffolds than in the cells cultured on the SF-CS scaffolds, and the proliferation of BMSCs cultured on both scaffolds was markedly increased compared with those cultured without scaffolds $(\mathrm{P}<0.05)$. These results indicate that the TGF- $\beta 1-S F-C S$ scaffolds significantly enhanced the attachment and proliferation of BMSCs under these conditions compared with the SF-CS scaffolds.

To evaluate the osteoblastic differentiation of the mesenchymal stem cells on the TGF- $\beta 1-S F-C S$ scaffolds and the SF-CS scaffolds, we measured ALP activity using spectrophotometry. The ALP activity of the BMSCs cultured on the TGF- $\beta 1-S F-C S$ scaffolds, the SF-CS scaffolds and the control group is shown in Fig. 6. For total ALP activity measurement on day 1 , there was no significant difference in OD values between the TGF- $\beta 1-S F-C S$, SF-CS and control groups $(\mathrm{P}>0.05)$. On days 4 to 10 , a significant difference in $\mathrm{OD}$ values was found between the scaffolds groups and the control group $(\mathrm{P}<0.01)$. The OD values in the TGF- $\beta 1-\mathrm{SF}-\mathrm{CS}$ group were the highest. This suggests that TGF- $\beta 1$ exerts an effect on the activity of BMSCs. As the culture time increased from days 4 to 10 , the growth trend of the OD values in the three groups increased rapidly. The OD values reached a peak at day 10 . This suggests that the TGF- $\beta 1-S F-C S$ scaffolds are a stable, prolonged culture system and stabilized TGF- $\beta 1$ greatly enhanced ALP activity.

Animals and clinical observations. A total of eighteen rabbits underwent the successful creation of a mandibular defect (Fig. 7A). All animals developed some degree of postoperative swelling at the incision site that resolved within one week of the operation with no functional consequences. The animals were allowed to heal for 4-12 weeks and then sacrificed for analysis. No rabbit developed an abscess or was sacrificed and excluded from analysis.
Analysis of 3D-CT images. To follow new bone formation and the development of bone unions within the defects, 3D images were captured 3 months postoperatively. Representative images from each group are shown in Fig. 7.

Analysis of the 3D-CT images confirmed the findings that the pure SF-CS scaffolds and the TGF- $\beta 1-S F-C S$ scaffold substitutes are bioactive and biocompatible with the host bone. In the TGF- $\beta 1-S F-C S$ scaffold group, the disappearance of the defect at 12 weeks after implantation indicated that the density of the newly formed bone was as high as that of the host bone, and that complete osteointegration of the defect area had been achieved (Fig. 7B). In comparison, in the pure SF-CS scaffold group, the volume and radiopacity of the newly formed bone are highly increased; however, the new bone formation failed to cover the defect completely, and bone formation occurred along the periphery of the defect area, which illustrated that the new bone had increased in density and quantity and had grown into the scaffold although incompletely (Fig. 7C). In the empty control group, the untreated defect exhibited no evidence of healing by itself even at 12 weeks (Fig. 7D).

Biomechanical evaluation. As shown in Fig. 8, the flexural strength of the implanted scaffold groups and the control group cultured for 4,8 and 12 weeks were compared. The flexural strength for the implanted scaffold groups gradually increased, indicating the occurrence of significant bone growth within both scaffolds. After 4 weeks, the flexural strength of the implanted scaffold groups $\left(23.9 \pm 6.223 \times 10^{4} \mathrm{~Pa}\right.$ and $29.9 \pm 6.481 \times 10^{4} \mathrm{~Pa}$ ) was significantly greater than the flexural strength of the empty defects $\left(20.9 \pm 3.610 \times 10^{4} \mathrm{~Pa}\right)$ $(\mathrm{P}<0.05)$. The increase in flexural strength was highest in the TGF- $\beta 1-S F-C S$ group, and the flexural strength values reached a peak at 12 weeks $\left(87.2 \pm 11.766 \times 10^{4} \mathrm{~Pa}\right)$.

Evaluation of local BMD. To quantify the level of calcification in the repaired mandibles, local BMD in all animals was measured on a DXA system at 4, 8 and 12 weeks postoperatively (Fig. 9). The BMD for the implanted scaffold groups gradually increased, indicating significant bone growth within both scaffolds. The BMD of the TGF- $\beta 1-S F-C S$ scaffold group was not significantly different from that in the SF-CS scaffold group at 4 weeks $(\mathrm{P}>0.05)$. However, at 8 weeks, the TGF- $\beta 1-S F-C S$ scaffold group showed a relatively higher BMD of $0.359 \pm 0.025 \mathrm{~g} / \mathrm{cm}^{2}$. In the SF-CS scaffold group, the local BMD was $0.227 \pm 0.047 \mathrm{~g} / \mathrm{cm}^{2}$, which was significantly lower than that in the TGF- $\beta 1-S F-C S$ scaffold group $(\mathrm{P}<0.05)$. At 12 weeks, the BMD of the TGF- $\beta 1-S F-C S$ scaffold group $\left(0.462 \pm 0.060 \mathrm{~g} / \mathrm{cm}^{2}\right)$ was significantly higher than the BMD of the SF-CS scaffold group $\left(0.362 \pm 0.038 \mathrm{~g} / \mathrm{cm}^{2}\right)(\mathrm{P}<0.05)$. The control group with a defect the same size as those implanted did not display any detectable BMD value in the DXA tests, thus, the contribution to the total density was negligible (data not shown).

Histomorphometric analysis of bone regeneration. Based on the in vivo histological study, all of the light microscope images showed the architecture of the scaffold clearly, which revealed that the scaffolds were not markedly deformed. In the TGF- $\beta 1-S F-C S$ scaffold group and the SF-CS scaffold group, 

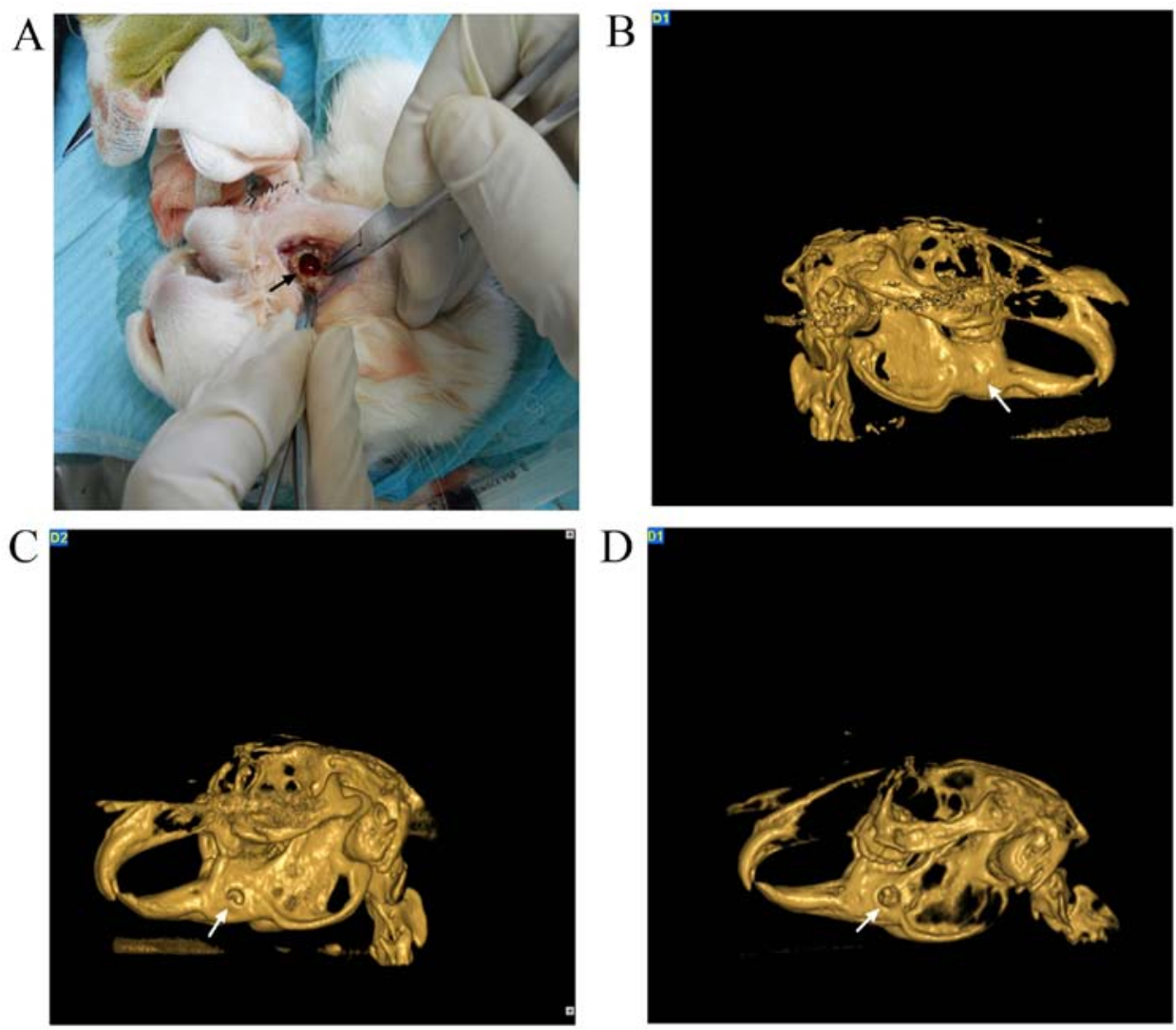

Figure 7. Surgical creation of the mandibular defect in rabbits and representative 3D-CT images for different groups at 12 weeks. (A) Surgical creation of a $8 \times 8 \mathrm{~mm}^{2}$ mandibular defect. (B) In the TGF- $\beta 1$-silk fibroin-chitosan (TGF- $\beta 1-S F-C S$ ) scaffold group, the defect had disappeared at 12 weeks after implantation. (C) In the pure silk fibroin-chitosan (SF-CS) scaffold group, the volume and radiopacity of the newly formed bone was greatly increased but the new bone formation failed to completely cover the defects. (D) In the empty control group, the untreated defect exhibited no evidence of healing by itself, even at 12 weeks.

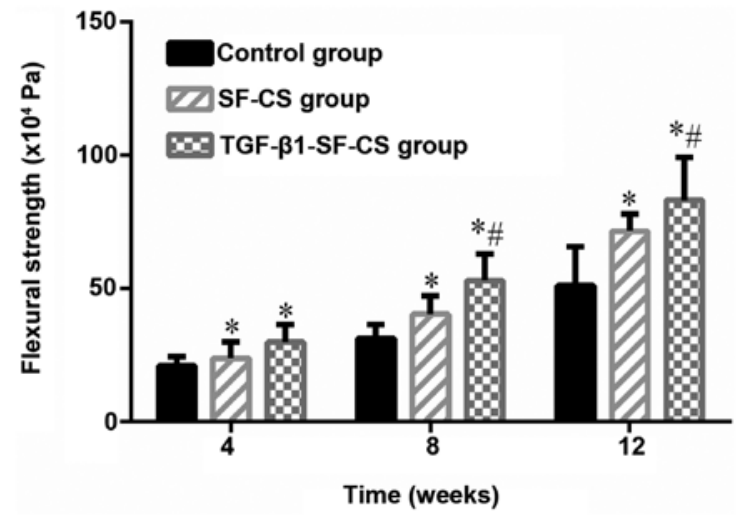

Figure 8. The flexural strength of the implanted scaffolds group and the control group following 4,8 and 12 weeks of culture. ${ }^{*} \mathrm{P}<0.05$ compared with the control group at the same time-point. ${ }^{*} \mathrm{P}<0.05$ compared with the silk fibroin-chitosan (SF-CS) scaffolds group. TGF- $\beta 1-$ SF-CS, TGF- $\beta 1$-silk fibroin-chitosan.

all the scaffolds implanted after 4 weeks are encapsulated by fibrous collagen, and some newly formed bone tissues are deposited at the interface of material and bone with the presence of active osteoblasts (Fig. 10A1 and B1). Moreover, a large proportion of osteoblasts have penetrated into the porous cavities, which accelerate the mineralization and regeneration of bone, and a large number of inflammatory cells are observable, as well as some newly generated tissues. Additionally,

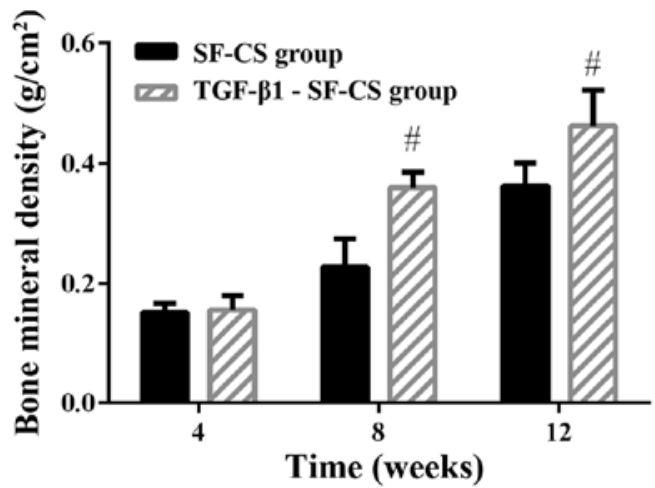

Figure 9. Determination of changes in the bone mineral density (BMD) in all animals, measured using dual energy X-ray absorptiometry (DXA) analysis at 4,8 and 12 weeks post-operatively. ${ }^{\#} \mathrm{P}<0.05$ compared with the silk fibroinchitosan (SF-CS) scaffolds group at the same time-point. TGF- $\beta 1-S F-C S$, TGF- $\beta 1$-silk fibroin-chitosan.

the interface between the SF-CS scaffold and natural bone is clearly visible, whereas in the TGF- $\beta 1$-SF-CS scaffold group the boundary between the material and host bone is unclear. In the control group, repaired tissues are not observable, and the defects are filled with few fiber-like tissues and adipocytes (Fig. 10C1).

At 8 weeks post-implantation, in the TGF- $\beta 1$-SF-CS scaffold group the boundary between material and host bone is 

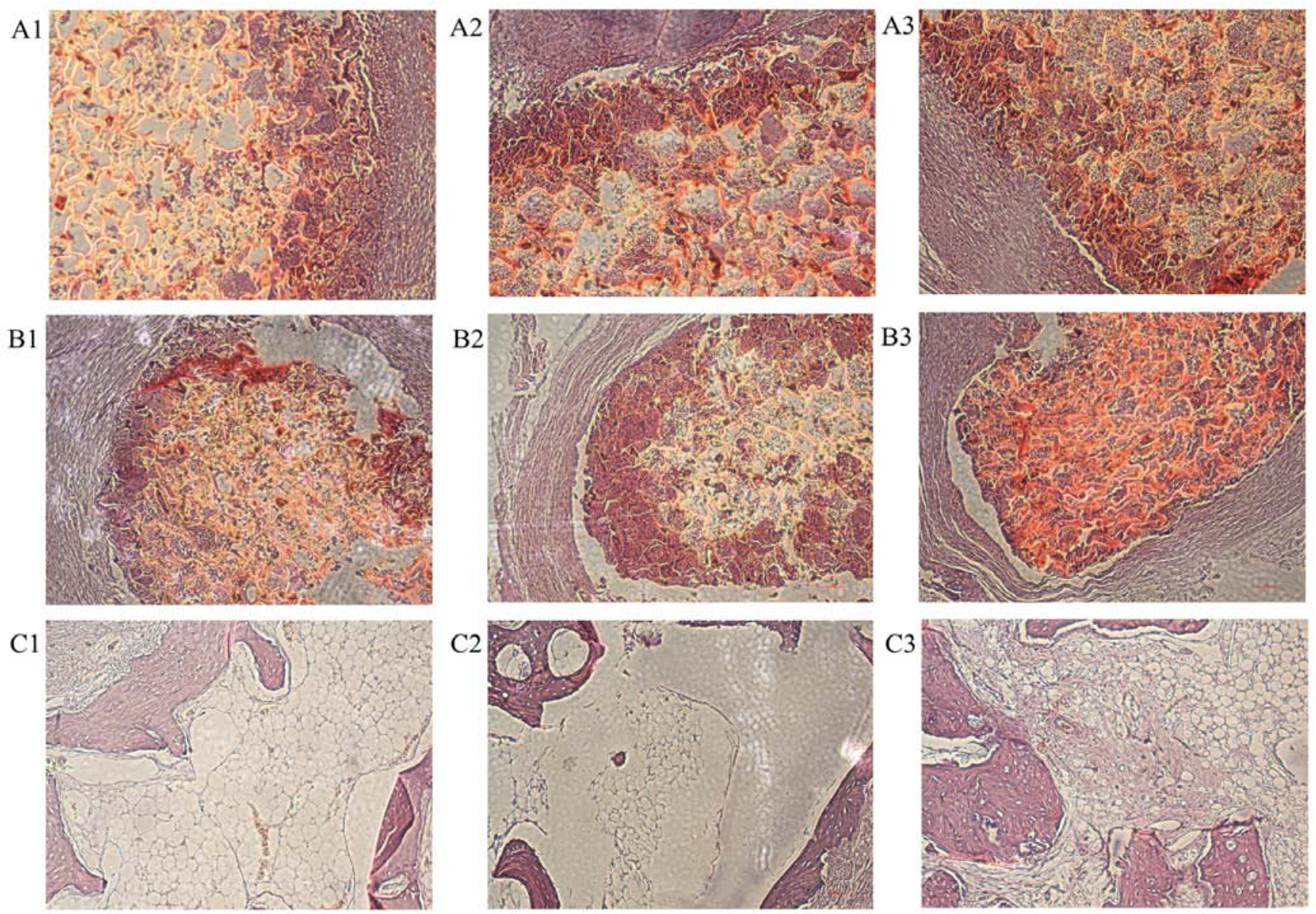

Figure 10. Sample histology of healed defects for the TGF- $\beta 1$-silk fibroin-chitosan (TGF- $\beta 1-S F-C S$ ) scaffolds, the silk fibroin-chitosan (SF-CS) scaffolds and the control group (light microscope, x100 magnification). At 4 weeks: (A1 and B1) All the scaffolds are encapsulated by fibrous collagen, some newly formed bone tissues are deposited at the interface between material and host bone with the presence of active osteoblasts. (C1) In the control group, repaired tissues are not present, and the defects are filled with few fiber-like tissues and adipocytes. At 8 weeks: (A2) In the TGF- $\beta 1$-SF-CS scaffold group, the boundary between material and host bone is unclear, new bone has regenerated and penetrated through the interconnective pores to the center of the scaffolds, increasing the quantity and density of the defect area. (B2) In the SF-CS scaffold group, the interface between scaffold and natural bone remains clearly visible, some newly formed bone tissues are deposited at the interface of material and bone with the presence of active osteoblasts. (C2) In the control group, the defects are filled with some fiber-like tissues and adipocytes. At 12 weeks: (A3) In the TGF- $\beta 1$-SF-CS scaffold group, the interface between material and host bone is hardly detectable and forms a close union without any gap. There is an ordered cell arrangement and an increased number of cells. (B3) In the SF-CS scaffold group, new bone formation is observable with more residual scaffold at the center of the defect compared with the TGF- $\beta 1$-SF-CS scaffold group. (C3) In the empty control group, the mandible defects exhibit no signs of recovery and there is limited encapsulation by fibrous tissues. Bony defects remain present in the center with new bone only formed at the periphery.

more unclear due to the sufficient formation of mature bone tissues which have grown into the pores of the artificial scaffold and bonded tightly with the material. With the implantation prolonged, new bone has regenerated and penetrated through the interconnective pores to the center of the scaffolds, increasing the quantity and density of the defect area, and decreasing the number of inflammatory cells (Fig. 10A2). In the SF-CS scaffold group, the interface between scaffold and natural bone was still clearly visible, some newly formed bone tissues have been deposited at the interface of material and bone with the presence of active osteoblasts (Fig. 10B2). In the control group, the defects are filled with some fiber-like tissues and adipocytes (Fig. 10C2).

The histological results of the TGF- $\beta 1-S F-C S$ scaffold group at 12 weeks show that the interface between material and host bone has formed a close union. There is an ordered cell arrangement and an increased number of cells. Additionally, inflammatory cells, including lymphocytes, are not observable. Despite some bone ingrowth from the interface region, there is insufficient bone formation in the central area (Fig. 10A3). In the SF-CS scaffold group, new bone formation is apparent with more residual scaffold at the center of the defect compared with that in the TGF- $\beta 1-S F-C S$ scaffold group. The SF-CS scaffolds still hold their pore structure and are unfilled by sufficient newly formed bone (Fig. 10B3). By contrast, in the empty control group, the mandible defects exhibited no signs of recovery with minimal encapsulation by fibrous tissues. Bony defects are still present in the center, the defects were filled with some fiber-like tissues and adipocytes, and new bone was only formed at the periphery. Despite some bone ingrowth from the interface region, there is insufficient bone formation in the central area (Fig. 10C3).

Quantitative determination of newly formed bone was performed by statistical analysis of the histological sections. Fig. 11 shows the NBV at each implantation period. Clearly, after 4 weeks post-implantation, the amount of newly formed bone in the TGF- $\beta 1$-SF-CS scaffold group increased markedly, much more than that in the pure SF-CS scaffold group. 


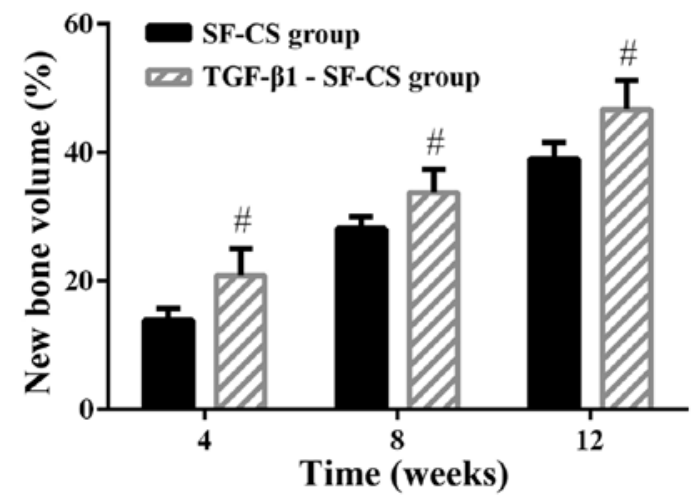

Figure 11. Measurement of new bone volume (NBV) in all animals at 4,8 and 12 weeks post-operatively. ${ }^{~} \mathrm{P}<0.05$ compared with the silk fibroin-chitosan (SF-CS) scaffolds group at the same time-point. TGF- $\beta 1-S F-C S$, TGF- $\beta 1$-silk fibroin-chitosan.

However, after that period, bone formation in the pure SF-CS scaffold slowed down, whereas in the TGF- $\beta 1-S F-C S$ scaffold group the speed of new bone formation gradually increased. At 12 weeks, NBV in the TGF- $\beta 1-S F-C S$ scaffold group was the highest. These results confirmed that at the latter stage of implantation, the TGF- $\beta 1-S F-C S$ scaffold achieved a higher efficiency of bone formation than pure SF-CS scaffolds, and in the long-term, the TGF- $\beta 1-S F-C S$ scaffolds showed far better biocompatibility and osteogenesis. The TGF- $\beta 1-S F-C S$ scaffolds group showed a healing percentage of $46.71 \pm 4.46 \%$, which was higher than the SF-CS scaffolds group $(38.97 \pm 2.63 \%)$ $(\mathrm{P}<0.05)$. The control group did not display marked bone formation in the NBV tests, so the contribution to the total NBV was negligible (data not shown).

\section{Discussion}

Growth factors may be incorporated directly into a polymeric scaffold to be used for tissue formation after scaffold fabrication $(21,22,31)$. Growth factor supplementation strategies have shown significant functional value in the context of bone tissue regeneration. Previous findings have 'immobilised' or 'incorporated' growth factors such as TGF- $\beta 1$ and fibroblast growth factor into tissue scaffold systems with sustained release properties (32). Active forms were used and inevitably involved processing steps which may have resulted in reduced bioactivity. In addition, the majority of scaffold release systems are hydrogel based, and the release of growth factors is by diffusion or degradation of the scaffold matrix. This often results in a 'burst' release and a compromise in the mechanical properties of the scaffold and in other properties required for bone engineering (33). In the present study, a composite scaffold design was constructed to increase the osteogenesis of BMSCs through the incorporation of TGF- $\beta 1$ during SF-CS scaffold fabrication, rather than after scaffold fabrication. This method was simple, convenient and had a high rate of success as well as easily controlling the of growth factor content. It also improved the loading content and loading efficiency of TGF- $\beta 1$ on the SF-CS scaffold. We analyzed the TGF- $\beta 1-S F-C S$ composite scaffolds for bone tissue engineering applications. Such a scaffold may be particularly suited for implantation into bone defects as it promotes the proliferation, migration and differentiation of cells as well as being osteoconductive. For this purpose, we added TGF- $\beta 1$ into the SF-CS scaffold to construct a 3D scaffold for the first time.

An optimum scaffold should meet certain criteria, such as a suitable 3D structure for cell growth and nutrient transport and optimal pore size to prevent cell loss from the scaffolds. We found that the SF-CS scaffolds had random porous microstructures, whether or not TGF- $\beta 1$ was added. Porous structures allow for the optimal interaction of the scaffold with the cells (34). Pore size determines the efficiency at which the cells seed into the scaffold (35). Small scaffold pores may result in pore occlusion by the cells, preventing cellular penetration whereas large pores prevent cell attachment due to a reduced area. It is necessary for the scaffold to have an adequate porosity; this includes the magnitude of the porosity, the pore size distribution and its interconnectivity. A pore size $>100 \mu \mathrm{m}$ and $<400 \mu \mathrm{m}$ is usually considered optimal for osteoconduction (36). In the present study, the TGF- $\beta 1-S F-C S$ scaffold had an open and interconnected pore network and a high degree of porosity. The inner pore size of the scaffold was approximately ten to three hundred microns, which led to uniform cell distribution inside the scaffolds. It was an ideal scaffold for interacting and integrating with the bone tissue. We also found that despite adding TGF- $\beta 1$ to the SF-CS scaffold, the porosity and swelling index of the scaffold did not markedly alter the shape and structure or morphology of the scaffolds.

CS is a polysaccharide found in the native ECM and it is known to play a critical role in sequestering growth factors within the matrix. Structural variations in the carbohydrate backbone, allows CS to possess varying levels of negative charges depending on the degree of sulfation $(37,38)$, making it attractive option for the development of growth factor-sequestering biomaterials. In addition to the non-specific, electrostatic growth factor-CS interactions, a similar study has also shown that TGF- $\beta 1$ may be adsorbed onto biomaterials such as SF composed of type I collagen (39). It is important to consider strategies to immobilize and pattern proteins, such as growth factors and other cytokines, to develop long-term tissue engineering solutions (40-44). Factor immobilization may offer numerous advantages, including improved protein stability and reduced diffusion, as well as increased localization of the therapeutic effects within the material. A previous study demonstrated that TGF- $\beta 1$ was immobilized in the SF-CS scaffold through ionic interactions and covalent bonds (45). The effectiveness of adsorbing TGF- $\beta 1$ onto the SF-CS scaffold may be due to protection of the molecule from proteolytic digestion, allowing a more sustained release of TGF- $\beta 1$ over time. This indicates that the growth factor remains bioactive within the matrix for a long period of time (46).

When constructing the TGF- $\beta 1-S F-C S$ scaffold for bone tissue engineering, it is critical to maintain the bioactivity of TGF- $\beta 1$ as during this process TGF- $\beta 1$ bioactivity is mostly like to be destroyed by lyophilization and methanol crosslinking. During the process of lyophilization, the use of a cryoprotectant may reduce or even prevent the adverse effects of stress on protein activity (47). Silk protein and CS may be used as a cryoprotectant to maintain the activity of TGF- $\beta 1(48,49)$. 
Klibanov proved that the conformation of protein treated with low concentrations of methanol was basically unchanged and the covalent structure of protein molecules was not destroyed (50). We implemented the following measures in manufacturing the TGF- $\beta 1-S F-C S$ scaffold to prevent the loss of TGF- $\beta 1$ bioactivity: i) setting the lyophilization temperature at $-40^{\circ} \mathrm{C}$ and using SF and CS as cryoprotectants to further maintain TGF- $\beta 1$ activity; ii) selecting a methanol concentration $<10 \%$; iii) designing the whole TGF- $\beta 1-S F-C S$ manufacturing procedure as a physical process. The results of the analysis of ALP activity and the CCK- 8 assay revealed that there was no clear degradation of TGF- $\beta 1$ bioactivity. We immobilized TGF- $\beta 1$ such that the total amount immobilized on the SF-CS scaffold was equivalent to the total soluble biomolecule content in the TGF- $\beta 1$ solution. This experiment revealed that, as expected, the freely soluble TGF- $\beta 1$ induced high bioactivity.

SEM analysis confirmed that subcellular microvillous and lamellopodia extensions were employed by adherent cells to establish anchorage fronts with the SF-CS substrate. Additionally, a BMSC growth differentiation study was performed to further evaluate the biocompatibility of these scaffolds. The seeding of BMSCs onto TGF- $\beta 1-S F-C S$ scaffolds resulted in a completely flat and elongated cell morphology, similar to what is typically observed in standard cell culture flasks. These observations confirmed the long-term cell viability and proliferation of BMSCs on TGF- $\beta 1-S F-C S$ scaffolds, assuring its biocompatibility.

Nominal differences in cellular adhesion were observed between BMSCs after osteogenesis induction. Additionally, these results suggested that the SF-CS scaffolds were suitable for the proposed in vitro studies as the initial attachment onto the surface as well as the spreading and subsequent growth of BMSCs was facilitated. The adhesion rate of BMSCs in the TGF- $\beta 1-S F-C S$ group and in the SF-CS group significantly exceeded those in the control groups $(\mathrm{P}<0.05)$. However, no statistically significant differences $(\mathrm{P}>0.05)$ were observed between the SF-CS and the TGF- $\beta 1-S F-C S$ scaffold groups. It proved that TGF- $\beta 1$ was unable to promote BMSC adhesion in the SF-CS scaffolds.

The number of viable cells at day 1 (after $24 \mathrm{~h}$ of cell attachment) was taken as a reference point to compare the growth and proliferation rate of BMSCs on the TGF- $\beta 1-S F-C S$ and SF-CS scaffolds. It was observed that the absorbance index of the tested groups increased in a time-dependent manner. However, there was a TGF- $\beta 1$-dependent effect of the scaffolds on cell proliferation rate. At day 1 , the viable cell number was not significantly different among the three groups, indicating that cell attachment to scaffolds was similar. With regard to cell growth, from day 3 , a significant difference $(\mathrm{P}<0.05)$ in cell number was observed between the scaffolds groups and the control group as well as between the TGF- $\beta 1-S F-C S$ and SF-CS scaffolds. These results indicated that TGF- $\beta 1$ significantly promoted the growth and proliferation of BMSCs after osteogenesis induction under these conditions. The in vitro experiments performed in the present study also suggest that TGF- $\beta 1$ may regulate bone formation through a direct effect on BMSCs after osteogenesis induction. Our results indicated a difference in the activity of BMSCs in the different types of scaffold which may be due to: i) the release of TGF- $\beta 1$ from TGF- $\beta 1-S F-C S$ scaffolds in a sustained manner thus, the released TGF- $\beta 1$ was able to reach the cells more quickly and homogeneously, and ii) TGF- $\beta 1$ maintained its bioactivity after being released from the TGF- $\beta 1-S F-C S$ scaffold. Through the ALP and CCK-8 assay results, we basically determined that in TGF- $\beta 1-S F-C S$ scaffolds, IGF-1 was evenly and continuously released within a certain time period.

Due to the rapid immobilization of TGF- $\beta 1$ in the SF-CS scaffold and the sustained and effective local release of growth factors after seeding BMSCs in the porous TGF- $\beta 1-S F-C S$ scaffold, as expected, the level of proliferation and differentiation of the BMSCs was controlled by the presence of TGF- $\beta 1$. The results obtained from the analysis of ALP activity and the CCK- 8 assay in vitro showed that the TGF- $\beta 1-S F-C S$ scaffolds did not contain products toxic to cells and the proliferation of BMSCs on the scaffolds increased regularly in a time-dependent manner. The SEM images revealed the spindle-like shape of the attached cells with filopodia-like extensions adhering to the scaffold and connecting to adjacent BMSCs. Evidence of cell-to-cell interactions and cell spreading may be considered as signs of healthy BMSCs and indicative of a noncytotoxic response of the cells on the supporting material $(51,52)$. In the present study, TGF- $\beta 1$ bioactivity was studied over the first 2 weeks of drug delivery. It has been shown that TGF- $\beta 1$ incorporated into the SF-CS scaffolds is capable of maintaining bioactivity over at least 2 weeks, suggesting that longer-term maintenance of bioactivity is feasible.

To evaluate the mechanical recovery of bone grafts in rabbit models of segmental radius defects, bending test configurations have been reported (53-55). Our studies have shown that both three-point bending resulted in similar outcomes when testing the mechanical integrity of rabbit mandible (53). In agreement with this study, the primary failure mode for bending was a short oblique fracture. Additionally, the reported primary failure zone was constrained to the location of the central contact in the three-point bending whereas the four-point mode was reported to have a more uniform stress distribution within the central loading span (56). Since the objective of this study was to evaluate the interfacial integration of the scaffold to the bone, three-point bending testing was selected, with the scaffold lying completely within the loading span. Other confounding factors such as loading to support span ratios, contact geometry and load rates were matched to the suggestions in the literature (56).

In the present study, bony union was achieved as early as 1 to 3 months after transplantation and an improved mandibular shape was observed after sacrifice. We also found that the BMD and NBV of the TGF- $\beta 1-S F-C S$ scaffold group was higher than the SF-CS scaffold group at 4 weeks postoperatively. This indicated that new bone formation and mineralization in the TGF- $\beta 1-S F-C S$ scaffold group surpassed that occurring during the repair process in the SF-CS scaffold group. Our data indicated that the SF-CS scaffold was feasible and conferred that TGF- $\beta 1$ possessses the potential physiological benefit of accelerated reconstruction. The results of CT scans, gross view and histological analyses consistently showed that the TGF- $\beta 1-S F-C S$ scaffold group had the strongest capacity for bone regeneration compared with the other groups. 
The capability of the TGF- $\beta 1-S F-C S$ scaffold to enhance the viability and proliferation of BMSCs as a function of time demonstrates its cytocompatibility and feasibility for bone tissue engineering applications. TGF- $\beta 1$ did not promote the activity and proliferation of osteoblasts significantly at early time-points; however, it had a marked effect when culturedfor longer periods of time (3-10 days), demonstrating that the effect of TGF- $\beta 1$, which promotes the activity and proliferation of BMSCs, is time-dependent. In the in vivo experiment, TGF- $\beta 1$ did not induce significantly more new bone formation at early time-points (4 weeks) whereas it had a marked effect at later time-points (after 8 weeks), demonstrating that the effect of TGF- $\beta 1$ which promotes the activity and proliferation of osteoblasts is time-dependent. These results indicate that correct TGF- $\beta 1$ delivery strategies greatly affect osteogenic differentiation and are of importance when designing a delivery system. The ideal duration of TGF- $\beta 1$ delivery is dependent on the drug delivery application. For example, for slowly progressing bone healing, controlled-release formulations leading to sustained improvements in patient symptoms and/or disease conditions allow for more convenient dosage and increased compliance with treatment.

Our data suggested that the anchorage of TGF- $\beta 1$ onto the SF-CS scaffold may achieve the intended natural configuration, as TGF- $\beta 1$ was protected and available for activation. The TGF- $\beta 1-S F-C S$ scaffold exerts positive effects on matrix production as well as the proliferation and differentiation of BMSCs. Our data supports the potential use of SF-CS as a biocompatible scaffold. Our findings demonstrated that TGF- $\beta 1-S F-C S$ scaffolds are suitable substrates for bone tissue engineering and TGF- $\beta 1$ confers the potential physiological benefit of accelerated reconstruction. We explored the immobilization of TGF- $\beta 1$ within the SF-CS scaffold to evaluate relative biomolecule bioactivity as a function of presentation modality. Future bone tissue engineering studies are warranted, focusing on how TGF- $\beta 1$ combined with the scaffold, and whether the sustained release of TGF- $\beta 1$ is maintained and enhanced in longer-term studies, or examining whether the culture of different types of cells on the TGF- $\beta 1-S F-C S$ scaffolds yields similar outcomes. Our future studies aim to examine the potential repair reaction of the TGF- $\beta 1-S F-C S$ scaffolds in a bone defect model in large animals. We also aim to explore additional soluble factors and exploit immobilization techniques to identify combinations of biomolecules capable of improving scaffolds. The materials developed here are also likely to be useful as 3D templates for bone tissue engineering.

In conclusion, we compared, for the first time to the best of our knowledge, the physiochemistry and osteogenesis of TGF- $\beta 1-S F-C S$ scaffolds and SF-CS scaffolds. Our results confirmed that TGF- $\beta 1$, a bioactive growth factor, has a significant capacity to improve the bioactivity of SF-CS scaffolds. The results showed that TGF- $\beta 1-S F-C S$ scaffolds exhibit good biocompatibility and extensive osteoconductivity with the host bone. Moreover, the introduction of TGF- $\beta 1$ to the SF-CS scaffolds markedly enhanced the efficiency of new bone formation, particularly 12 weeks after implantation. The TGF- $\beta 1-S F-C S$ scaffolds possessed as good biocompatibility and osteogenesis as the hybrid ones. All these results indicated that the TGF- $\beta 1-S F-C S$ scaffolds fulfiled the basic requirements of an ideal scaffold for use in bone tissue engineering, and have the potential to be applied in orthopedic, reconstructive and maxillofacial surgery.

\section{Acknowledgements}

The present study was supported by the Science and Technology Plan Project of Liaoning Province (grant no. 2012B-00002012225082).

\section{References}

1. Vacanti JP and Langer R: Tissue engineering: the design and fabrication of living replacement devices for surgical reconstruction and transplantation. Lancet 354 (Suppl 1): SI32-SI34, 1999.

2. Scheller EL, Krebsbach PH and Kohn DH: Tissue engineering: state of the art in oral rehabilitation. J Oral Rehabil 36: 368-389, 2009.

3. Hankenson KD, Dishowitz M, Gray C and Schenker M: Angiogenesis in bone regeneration. Injury 42: 556-561, 2011.

4. Marsell R and Einhorn TA: The biology of fracture healing. Injury 42: 551-555, 2011.

5. Andrew JG, Hoyland J, Andrew SM, Freemont AJ and Marsh D: Demonstration of TGF-beta $1 \mathrm{mRNA}$ by in situ hybridization in normal human fracture healing. Calcif Tissue Int 52: 74-78, 1993.

6. Baylink DJ, Finkelman RD and Mohan S: Growth factors to stimulate bone formation. J Bone Miner Res 8 (Suppl 2): S565-S572, 1993.

7. Bonewald LF and Mundy GR: Role of transforming growth factor-beta in bone remodeling. Clin Orthop Relat Res 250: 261-276, 1990.

8. Connelly JT, Wilson CG and Levenston ME: Characterization of proteoglycan production and processing by chondrocytes and BMSCs in tissue engineered constructs. Osteoarthritis Cartilage 16: 1092-1100, 2008.

9. Mouw JK, Connelly JT, Wilson CG, Michael KE and Levenston ME: Dynamic compression regulates the expression and synthesis of chondrocyte-specific matrix molecules in bone marrow stromal cells. Stem Cells 25: 655-663, 2007.

10. Johnstone B, Hering TM, Caplan AI, Goldberg VM and Yoo JU: In vitro chondrogenesis of bone marrow-derived mesenchymal progenitor cells. Exp Cell Res 238: 265-272, 1998.

11. Murphy CM, O'Brien FJ, Little DG and Schindeler A: Cell-scaffold interactions in the bone tissue engineering triad. Eur Cell Mater 26: 120-132, 2013.

12. Roberts AB and Sporn MB: Physiological actions and clinical applications of transforming growth factor-beta (TGF-beta). Growth Factors 8: 1-9, 1993.

13. Pittenger MF, Mackay AM, Beck SC, Jaiswal RK, Douglas R, Mosca JD, Moorman MA, Simonetti DW, Craig S and Marshak DR: Multilineage potential of adult human mesenchymal stem cells. Science 284: 143-147, 1999.

14. Cashman JD, Eaves AC, Raines EW, Ross R and Eaves CJ: Mechanisms that regulate the cell cycle status of very primitive hematopoietic cells in long-term human marrow cultures. I. Stimulatory role of a variety of mesenchymal cell activators and inhibitory role of TGF-beta. Blood 75: 96-101, 1990.

15. Spinella-Jaegle S, Roman-Roman S, Faucheu C, Dunn FW, Kawai S, Galléa S, Stiot V, Blanchet AM, Courtois B, Baron R and Rawadi G: Opposite effects of bone morphogenetic protein-2 and transforming growth factor-betal on osteoblast differentiation. Bone 29: 323-330, 2001

16. Park SJ, Lee KY, Ha WS and Park SY: Structural changes and their effect on mechanical properties of silk fibroin/chitosan blends. J Appl Polym Sci 74: 2571-2575, 1999.

17. El Sayed K, Marzahn U, John T, Hoyer M, Zreiqat H, Witthuhn A, Kohl B, Haisch A and Schulze-Tanzil G: PGA-associated heterotopic chondrocyte cocultures: implications of nasoseptal and auricular chondrocytes in articular cartilage repair. J Tissue Eng Regen Med 7: 61-72, 2013.

18. De Santis R, Gloria A, Russo T, D'Amora U, Zeppetelli S, Dionigi C, Sytcheva A, Herrmannsdörfer T, Dediu V and Ambrosio L: A basic approach toward the development of nanocomposite magnetic scaffolds for advanced bone tissue engineering. J Appl Polym Sci 122: 3599-3605, 2011.

19. Tong S, Xu DP, Liu ZM and Wang XK: Construction and in vitro characterization of three-dimensional silk fibroinchitosan scaffolds. Dent Mater J 34: 475-484, 2015. 
20. Gobin AS, Froude VE and Mathur AB: Structural and mechanical characteristics of silk fibroin and chitosan blend scaffolds for tissue regeneration. J Biomed Mater Res A 74: 465-473, 2005.

21. Whang K, Tsai DC, Nam EK, Aitken M, Sprague SM, Patel PK and Healy KE: Ectopic bone formation via rhBMP-2 delivery from porous bioabsorbable polymer scaffolds. J Biomed Mater Res 42: 491-499, 1998.

22. Uebersax L, Merkle HP and Meinel L: Insulin-like growth factor I releasing silk fibroin scaffolds induce chondrogenic differentiation of human mesenchymal stem cells. J Control Release 127: 12-21, 2008.

23. Li C, Vepari C, Jin HJ, Kim HJ and Kaplan DL: Electrospun silk-BMP-2 scaffolds for bone tissue engineering. Biomaterials 27: 3115-3124, 2006.

24. Hosseinkhani H, Hosseinkhani M, Khademhosseini A and Kobayashi $\mathrm{H}$ : Bone regeneration through controlled release of bone morphogenetic protein-2 from 3-D tissue engineered nanoscaffold. J Control Release 117: 380-386, 2007.

25. Luginbuehl V, Wenk E, Koch A, Gander B, Merkle HP and Meinel L: Insulin-like growth factor I-releasing alginate-tricalciumphosphate composites for bone regeneration. Pharm Res 22: 940-950, 2005

26. Chung YI, Ahn KM, Jeon SH, Lee SY,Lee JH and Tae G: Enhanced bone regeneration with BMP-2 loaded functional nanoparticlehydrogel complex. J Control Release 121: 91-99, 2007.

27. Li B, Brown KV, Wenke JC and Guelcher SA: Sustained release of vancomycin from polyurethane scaffolds inhibits infection of bone wounds in a rat femoral segmental defect model. J Control Release 145: 221-230, 2010.

28. Long JL and Tranquillo RT: Elastic fiber production in cardiovascular tissue-equivalents. Matrix Biol 22: 339-350, 2003.

29. Shi J, Wang A, Sen S, Wang Y, Kim HJ, Mitts TF and Hinek A: Insulin induces production of new elastin in cultures of human aortic smooth muscle cells. Am J Pathol 180: 715-726, 2012.

30. Kim UJ, Park J, Kim HJ, Wada $M$ and Kaplan DL: Three-dimensional aqueous-derived biomaterial scaffolds from silk fibroin. Biomaterials 26: 2775-2785, 2005.

31. Li C, Vepari C, Jin HJ, Kim HJ and Kaplan DL: Electrospun silk-BMP-2 scaffolds for bone tissue engineering. Biomaterials 27 : 3115-3124, 2006.

32. Chou CH, Cheng WT, Lin CC, Chang CH, Tsai CC and Lin FH: TGF-beta1 immobilized tri-co-polymer for articular cartilage tissue engineering. J Biomed Mater Res B Appl Biomater 77: 338-348, 2006

33. Sohier J, Moroni L, van Blitterswijk C, de Groot K and Bezemer JM: Critical factors in the design of growth factor releasing scaffolds for cartilage tissue engineering. Expert Opin Drug Deliv 5: 543-566, 2008.

34. Lyons F, Partap S and O'Brien FJ: Part 1: scaffolds and surfaces. Technol Health Care 16: 305-317, 2008.

35. Mooney DJ, Baldwin DF, Suh NP, Vacanti JP and Langer R: Novel approach to fabricate porous sponges of poly (D,L-lacticco-glycolic acid) without the use of organic solvents Biomaterials 17: 1417-1422, 1996.

36. Chung HJ and Park TG: Surface engineered and drug releasing pre-fabricated scaffolds for tissue engineering. Adv Drug Deliv Rev 59: 249-262, 2007.

37. Raman R, Sasisekharan V and Sasisekharan R: Structural insights into biological roles of protein-glycosaminoglycan interactions. Chem Biol 12: 267-277, 2005

38. Gama CI, Tully SE, Sotogaku N, Clark PM, Rawat M, Vaidehi N, Goddard WA III, Nishi A and Hsieh-Wilson LC: Sulfation patterns of glycosaminoglycans encode molecular recognition and activity. Nat Chem Biol 2: 467-473, 2006.

39. Hempel U, Hintze V, Möller S, Schnabelrauch M, Scharnweber D and Dieter P: Artificial extracellular matrices composed of collagen I and sulfated hyaluronan with adsorbed transforming growth factor $\beta 1$ promote collagen synthesis of human mesenchymal stromal cells. Acta Biomater 8: 659-666, 2012.
40. Ker EDF, Chu B, Phillippi JA, Gharaibeh B, Huard J, Weiss LE and Campbell PG: Engineering spatial control of multiple differentiation fates within a stem cell population. Biomaterials 32 : 3413-3422, 2011

41. Shen YH, Shoichet MS and Radisic M: Vascular endothelial growth factor immobilized in collagen scaffold promotes penetration and proliferation of endothelial cells. Acta Biomater 4: 477-489, 2008.

42. Oh SH, Kim TH and Lee JH: Creating growth factor gradients in three dimensional porous matrix by centrifugation and surface immobilization. Biomaterials 32: 8254-8260, 2011.

43. Anderson SM, Chen TT, Iruela-Arispe ML and Segura T: The phosphorylation of vascular endothelial growth factor receptor-2 (VEGFR-2) by engineered surfaces with electrostatically or covalently immobilized VEGF. Biomaterials 30: 4618-4628, 2009.

44. Martin TA, Caliari SR, Williford PD, Harley BA and Bailey RC: The generation of biomolecular patterns in highly porous collagen-GAG scaffolds using direct photolithography. Biomaterials 32: 3949-3957, 2011.

45. Weadock K, Olson RM and Silver FH: Evaluation of collagen crosslinking techniques. Biomater Med Devices Artif Organs 11: 293-318, 1983-1984.

46. Hortensius RA and Harley BA: The use of bioinspired alterations in the glycosaminoglycan content of collagen-GAG scaffolds to regulate cell activity. Biomaterials 34: 7645-7652, 2013.

47. Haines AH: Non-equivalence of D-and L-trehalose in stabilising alkaline phosphatase against freeze-drying and thermal stress. Is chiral recognition involved? Org Biomol Chem 4: 702-706, 2006.

48. Kreilgaard L, Jones LS, Randolph TW, Frokjaer S, Flink JM, Manning MC and Carpenter JF: Effect of Tween 20 on freeze-thawing- and agitation-induced aggregation of recombinant human factor XIII. J Pharm Sci 87: 1597-1603, 1998.

49. Pikal-Cleland KA and Carpenter JF: Lyophilization-induced protein denaturation in phosphate buffer systems: monomeric and tetrameric beta-galactosidase. J Pharm Sci 90: 1255-1268, 2001.

50. Klibanov AM: Enzymatic catalysis in anhydrous organic solvents. Trends Biochem Sci 14: 141-144, 1989.

51. Nwe N, Furuike T and Tamura H: The mechanical and biological properties of chitosan scaffolds for tissue regeneration templates are significantly enhanced by chitosan from Gongronella butleri. Materials (Basel) 2: 374-398, 2009.

52. Neamnark A, Sanchavanakit N, Pavasant P, Bunaprasert T, Supaphol P and Rujiravanit R: In vitro biocompatibility evaluations of hexanoyl chitosan film. Carbohydr Polym 68: 166-172, 2007.

53. Kim J, Yang HJ, Cho TH, Lee SE, Park YD, Kim HM, Kim IS, Seo YK, Hwang SJ and Kim SJ: Enhanced regeneration of rabbit mandibular defects through a combined treatment of electrical stimulation and rhBMP-2 application. Med Biol Eng Comput 51: 1339-1348, 2013

54. Cui X, Zhang B, Wang Y and Gao Y: Effects of chitosan-coated pressed calcium sulfate pellet combined with recombinant human bone morphogenetic protein 2 on restoration of segmental bone defect. J Craniofac Surg 19: 459-465, 2008.

55. Shafiei Z, Bigham AS, Dehghani SN and Nezhad ST: Fresh cortical autograft versus fresh cortical allograft effects on experimental bone healing in rabbits: radiological, histopathological and biomechanical evaluation. Cell Tissue Bank 10: 19-26, 2009.

56. Draper ER and Goodship AE: A novel technique for four-point bending of small bone samples with semi-automatic analysis. J Biomech 36: 1497-1502, 2003. 